\title{
A Study of 30-Storey Dual System Building with Different Soil Conditions
}

\author{
Sumit Pahwa *, Devkinandan Prajapati **, Utkarsh Jain***, \\ * (Ass. Professor, Department of Civil Engineering, Alpine Institute of Technology, Indore, M.P., India) \\ ** (Research Scholar, Department of Civil Engineering Alpine Institute, of Technology, Indore, M.P., India) \\ *** (Ass. Professor, Department of Civil Engineering, Indore Institute of Technology, Indore, M.P., India)
}

\begin{abstract}
The structural system of a high-rise building with Shear walls are lateral load resisting structural systems which provide stability to structures from lateral loads like wind and seismic Loads. The design of multi-storey building it is generally constructed on assumed that underlying soil are Hard, Medium and Soft. A Multi-storey building with RC-Shear wall is to have good lateral load resisting System along with gravity load system for safety of occupant and for better performance of structure even in most adverse condition. As a result the accuracy in assessing structural safely during earthquake cannot be accounted accurately. So investigation of energy transfer mechanism from soils to buildings during earthquake is vital for the design of earthquake resistant structures and for retrofitting existing structures. Hence the soil -structure interaction analysis of framed structures is the main focus of this study. The effects of soil-structure interaction are analyzed for typical multi- storey building resting on different soils. In Our Project contains a brief description and analysis of Symmetrical frame having 30 storey building with shear wall and without shear wall with different types of soil condition for highly seismic area i.e. zone-5, thoroughly discussed structural analysis of a building to explain the application of shear wall. The design analysis of the multi storied building in our project is done through software STAAD.Pro.
\end{abstract}

Keywords: Base Shear, Drift Reduction factor, Dual System, Soil-Structure Interaction, Storey Drift, Shear wall.

\section{INTRODUCTION}

Reinforced concrete framed buildings are adequate for resisting both vertical and the horizontal loads acting on them. When the buildings are tall say more than 10 storey's or so, beam and column sizes work out large reinforcement at beam-column junctions works out quite heavy, so that there is a lot of congestion at these joints and it is difficult to place and vibrate concrete at these places, which fact, does not contribute to the safety of buildings. These practical difficulties call for introduction of shear wall in multi-storey buildings. A shear wall is a structural element used to resist lateral/horizontal/shear force parallel to the plane of wall is called shear wall.

- Shear wall resist the lateral or horizontal force by cantilever action for slender wall where bending deformation is dominant.

- Shear wall resist the lateral or horizontal force by truss action for short wall where shear defo rmation is dominant.

\section{SOIL-STRUCTURE INTERACTION} (SSI)

The approach in which the response of the soil influences the movement of the shape and the movement of the structure impacts the response of the soil is named as Soil-Shape interaction (SSI). Soil- structure interaction (SSI) has been accustomed as an important steady which can decidedly affect the motion of base, relative building response and motion of surrounding soil. Typically constructing soil interplay consists of two places kinematic interaction and Dynamic interaction. The former end result of wave nature is excitation and is manifested via the scattering of incident waves from basis system and via filtering impact of the inspiration that may be stiffer than the soil. Consequently it could no longer observe the higher frequency deformations of soil. This interaction depends on attitude of incidence, frequency, kind of incident waves, shape of foundation and depth of basis. It develops because of presence of stiff basis elements on or in soil reason basis movement to deviate from free-subject motions. The later is because of inertia forces of constructing and of the foundation which act on soil because of contact vicinity. And it depends at the mass and height of the constructing and the mass and depth of foundation, on the relative stiffness of soil as compared with the constructing and on the form of basis. It develops in shape due to its very own vibrations which offers rise to base shear and base second, which in turn cause displacements of the foundation relative to free area. At low stage of 
ground shaking, kinematic impact is extra dominant inflicting boom of period. Observations from current earthquakes have proven that the response of the inspiration and soil can substantially have an effect on the general structural response.

\begin{tabular}{|c|c|c|c|}
\hline $\begin{array}{c}\text { Type of } \\
\text { Soil }\end{array}$ & $\begin{array}{c}\text { Hard } \\
\text { Rock/Soil }\end{array}$ & Medium & Soft \\
\hline SSI & 1 & 2 & 3 \\
\hline
\end{tabular}

\section{METHODS OF ANALYSIS}

Equivalent Static Analysis, All design against earthquake effects must consider the dynamic nature of the load. However, for simple regular structures, analysis by equivalent linear static methods is often sufficient. This is permitted in most codes of practice for regular, low- to medium-rise buildings and begins with an estimate of peak earthquake load calculated as a function of the parameters given in the code. Equivalent static analysis can therefore work well for low to medium-rise buildings without significant coupled lateral-torsion modes, in which only the first mode in each direction is of Significance. Tall buildings where second and higher modes can be important, or buildings with tensional effects, are much less suitable for the method, and require more complex methods to be used in these circumstances.

\section{BUILDING DETAILS}

The building considered here is a residential building Having G +29 storied located in seismic zone $\mathrm{V}$ and for Earthquake loading, the provisions of the IS:1893(Part1)- 2002 is considered. The plan of building is shown in figure. The plan dimension of the building is $20 \mathrm{~m} \mathrm{X} 30 \mathrm{~m}$. Height of each storey is $3 \mathrm{~m}$. The floor plans were divided into four by six bays in such a way that center to center distance between two grids is $5 \mathrm{~m}$ by $5 \mathrm{~m}$ respectively. Detail of the building shown in Table 1.

\subsection{Types of Frame-}

4.1.1. One bare frame prepared without shear wall [B$\mathrm{S}(\mathrm{W})]$,

4.1.2. Second frame $250 \mathrm{~mm}$ thick L-Type RC-Shear wall apply on all both corner of the bare frame throughout full height of building [B-S (1)].

4.1.3. Third frame $250 \mathrm{~mm}, 200 \mathrm{~mm}$ and $150 \mathrm{~mm}$ thickness of L-Type RC- Shear wall are used and Thickness of shears wall will be gradually reduced throughout the height of the building [B-S (2)].

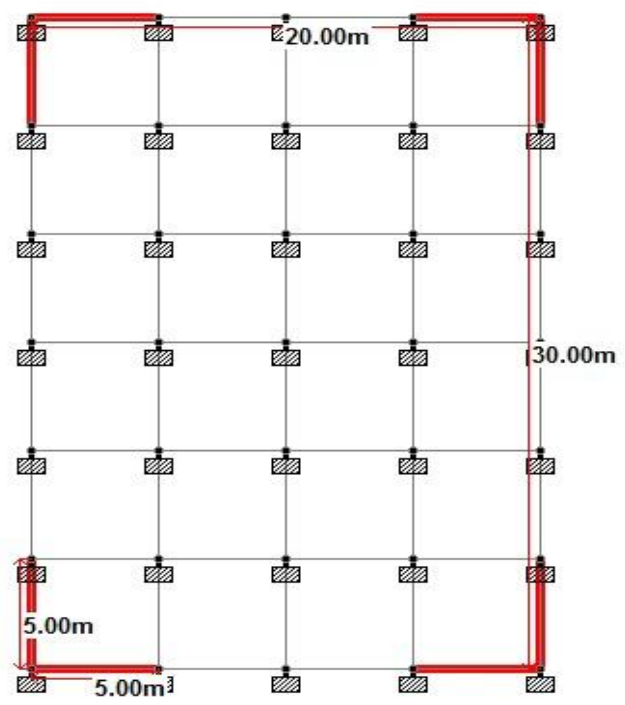

Fig. 1 Plan of Building with Position of Shear Wall

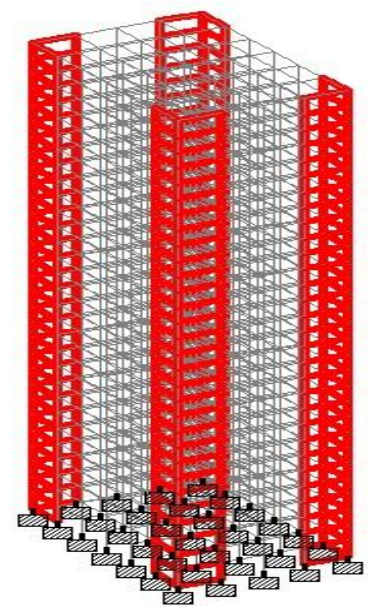

Fig. 2 3D Skeleton View of Frame with Position of Shear Wall

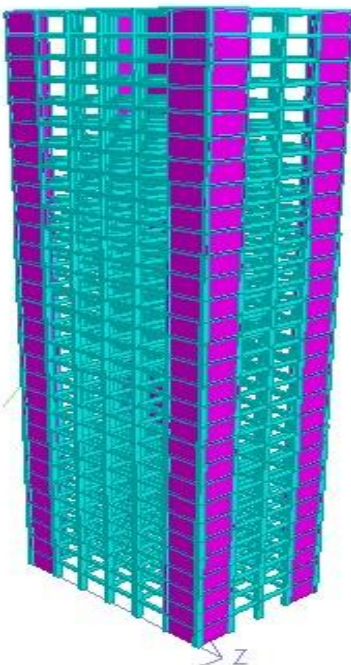

Fig. 3 3D View of Frame with Position of Shear wall 


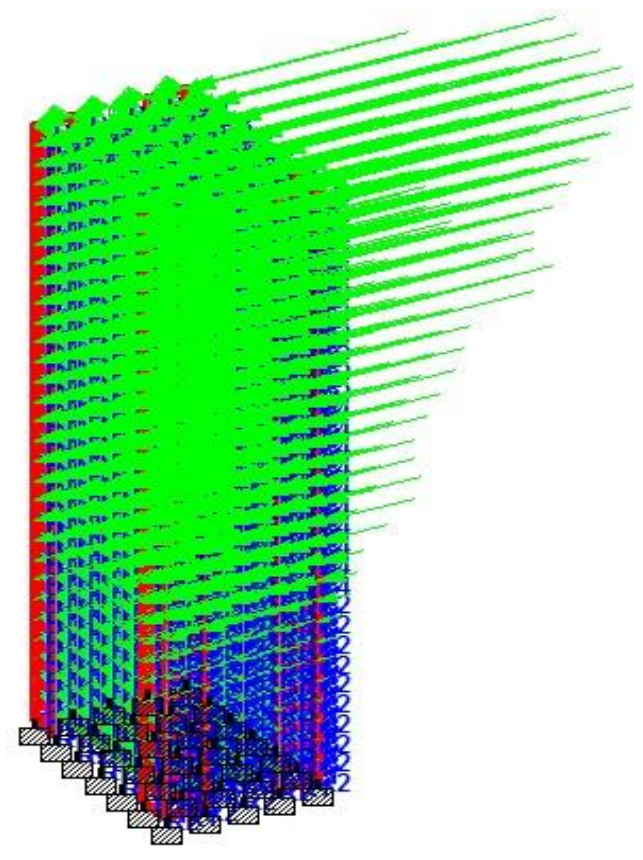

Fig. 4 3D View of Frame with Shear wall Position Earthquake Loading.

TABLE-1 FOR 30 STOREY BUILDING

\begin{tabular}{|c|c|c|c|}
\hline Plan dimension & \multicolumn{3}{|c|}{$20 \mathrm{mX30m}$} \\
\hline $\begin{array}{l}\text { Total Height of } \\
\text { Building }\end{array}$ & \multicolumn{3}{|c|}{$90 \mathrm{~m}$} \\
\hline Height of each storey & \multicolumn{3}{|c|}{$3 \mathrm{~m}$} \\
\hline Thickness of slab & \multicolumn{3}{|c|}{$125 \mathrm{~mm}$} \\
\hline $\begin{array}{l}\text { Grade of reinforcing } \\
\text { steel }\end{array}$ & \multicolumn{3}{|c|}{$\mathrm{Fe} 500$} \\
\hline Density of concrete & \multicolumn{3}{|c|}{$25 \mathrm{KN} / \mathrm{m}^{3}$} \\
\hline $\begin{array}{c}\text { Grade of concrete for } \\
\text { Beams, Column and } \\
\text { Shear Wall }\end{array}$ & \multicolumn{3}{|c|}{ M 25} \\
\hline Seismic zone & \multicolumn{3}{|c|}{ V } \\
\hline Seismic Zone factor & \multicolumn{3}{|c|}{0.36} \\
\hline Soil condition & Hard & Medium & $\begin{array}{c}\text { Sof } \\
t\end{array}$ \\
\hline Soil interaction Factor & 1 & 2 & 3 \\
\hline $\begin{array}{c}\text { Response Reduction } \\
\text { Factor }\end{array}$ & \multicolumn{3}{|c|}{5} \\
\hline Importance factor (I) & \multicolumn{3}{|c|}{1} \\
\hline Type of Structure & \multicolumn{3}{|c|}{1} \\
\hline Damping ratio (DM) & \multicolumn{3}{|c|}{0.05} \\
\hline Beam size R.C.C. & \multicolumn{3}{|c|}{$300 \mathrm{~mm} X 500 \mathrm{~mm}$} \\
\hline Type of Support & \multicolumn{3}{|c|}{ Fixed Support } \\
\hline \multirow[t]{3}{*}{ Column size R.C.C } & Ht. $0 \mathrm{~m}$ to $30 \mathrm{~m}$ & \multicolumn{2}{|c|}{$\begin{array}{c}700 \mathrm{~mm} \mathrm{X} \\
700 \mathrm{~mm}\end{array}$} \\
\hline & Ht. $30 \mathrm{~m}$ to $60 \mathrm{~m}$ & \multicolumn{2}{|c|}{$\begin{array}{c}600 \mathrm{~mm} \mathrm{X} \\
600 \mathrm{~mm}\end{array}$} \\
\hline & Ht. $60 \mathrm{~m}$ to $90 \mathrm{~m}$ & \multicolumn{2}{|c|}{$\begin{array}{c}400 \mathrm{~mm} \mathrm{X} \\
400 \mathrm{~mm}\end{array}$} \\
\hline \multirow{3}{*}{$\begin{array}{c}\text { Thickness of Shear } \\
\text { Wall }\end{array}$} & \multicolumn{3}{|c|}{$250 \mathrm{~mm}$ (Ht $0 \mathrm{~m}$ to $27 \mathrm{~m})$} \\
\hline & \multirow{2}{*}{\multicolumn{3}{|c|}{$200 \mathrm{~mm}(\mathrm{Ht} 27 \mathrm{~m}$ to $60 \mathrm{~m})$}} \\
\hline & & & $150 \mathrm{~mm}$ (Ht $60 \mathrm{~m}$ to $90 \mathrm{~m})$ \\
\hline
\end{tabular}

\section{LOAD COMBINATIONS}

The gravity loads and earthquake loads will be taken for analysis. The basic loads are Dead loads (DL), Imposed load (LL), Earthquake load (EQ) along $\mathrm{X}$ and $\mathrm{Z}$ in positive and negative direction. As per IS 1893 (Part I): 2002 Clause no. 6.3.1.2, the following Earthquake load cases have to be considered for analysis.

$$
\begin{array}{ll}
1.5(\mathrm{DL}+\mathrm{LL}) & 0.9 \mathrm{DL} \pm 1.5 \mathrm{EQX} \\
0.9 \mathrm{DL} \pm 1.5 \mathrm{EQZ} & 1.5(\mathrm{DL} \pm \mathrm{EQZ}) \\
1.5(\mathrm{DL} \pm \mathrm{EQX}) & 1.2(\mathrm{DL}+\mathrm{LL} \pm \mathrm{EQX}) \\
1.2(\mathrm{DL}+\mathrm{LL} \pm \mathrm{EQZ}) &
\end{array}
$$

\section{ANALYSIS OF BUILDING}

Multi storied G+29 building with fixed support base subjected to seismic forces and Gravity force were analyzed under different soil condition like hard, medium and soft. The dead load and live load are considered as per IS-875(part 1 \&2) and earthquake loading IS: 1893 (Part1)-2002 is used. The buildings were analysis carried out for Zone 5 using Equivalent Static Method. The software used for analysis is STAAD.Pro. Different parameters such as Lateral Displacement, story drift, deflection, base shear and time period are studied for the models. We are Constructing 9 Models of 30 Storey Building. Three model of B-S (W) for Soil Interaction Factor-1, $2 \&$ 3, Three Models for B-S (1) for Soil Interaction Factor-1, $2 \& 3$ and Three Modes for B-S (2) for Soil Interaction Factor-1, 2 \& 3

\begin{tabular}{|l|l|l|}
\hline B-S (W) SOL-1 & B-S(1) SOL-1 & B-S (2) SOL-1 \\
\hline B-S (W) SOL-2 & B-S (1) SOL-2 & B-S (2) SOL-2 \\
\hline B-S (W) SOL-3 & B-S (1) SOL-3 & B-S(2) SOL-3 \\
\hline
\end{tabular}

\section{RESULTS AND DISCUSSIONS}

After Analysis, We are getting Lateral displacement at every storey for all models and with the help of Lateral displacement Drift according to storey height are calculated for all models in every soil conditions. After Drift calculation Drift reduction factor are calculated.

Design Base Shear- The design seismic base shear, $V_{B}$ is distributed to different floor levels along the height of the building as per the clause 7.7.1 of IS 1893 (Part 1): 2002;

Where

$\mathrm{Qi}=$ Design lateral force at floor ' $\mathrm{i}$ '

$\mathrm{Wi}=$ Seismic weight of floor ' $\mathrm{i}$ '

hi $=$ Height of floor i measured from base, and $\mathrm{n}=$ Number of stores in the building is the number of levels at which masses are located 


$$
Q_{i}=V_{B} \frac{W_{i} h_{i}^{2}}{\sum_{j=1}^{n} W_{j} h_{j}^{2}}
$$

Drift- Calculate the deflection in the Column at every storey, based on more than just flexure. Drift is the deflection of the Colum/wall at story (i) minus the deflection of the wall at story (i-1), divided by the height of the wall at story i.

$$
(\Delta \mathbf{i}-\Delta \mathbf{i}-1) / h \mathbf{i}
$$

This is commonly expressed as a fraction of the span (h), such as $1 / 400 *$ span, or as the drift angle, $\arctan \quad((\Delta \mathrm{i}-\quad \Delta \mathrm{i}-1) / \mathrm{hi})$ As the name implies, shear deformation is significant for shear walls and needs to be considered.

Drift Reduction Factor (RC)- DRF is the Drift in the RC- Bare frame without shear wall [B-S (W)] minus Drift in the RC- Frame with Shear Wall [B-S (1) or B$S$ (2)], Divided by the Drift in the RC- Bare frame without shear wall [B-S (W)]. We are denoting DRF by RC-1 and RC-2.

Drift Reduction Factor (RC-1) due to Frame with shear wall having Homogenous Thickness throughout full height of Building [B-S (1)]

RC-1 = Drift $[B-S(W)]-$ Drift $[B-S(1)] /$ Drift in [B$\mathrm{S}(\mathrm{W})]$
Drift Reduction Factor (RC-2) due to Frame with shear wall having gradually changing thickness throughout the height of Building ( $\mathrm{RC}-2)$

RC-2 $=$ Drift in $[\mathrm{B}-\mathrm{S}(\mathrm{W})]-$ Drift in $[\mathrm{B}-\mathrm{S}(2)] /$ Drift

\begin{tabular}{|c|c|c|c|c|c|c|c|c|c|c|c|c|c|c|c|}
\hline \multicolumn{16}{|c|}{ TABLE-2 OF DRIFT AND DRIFT REDUCTION FACTOR AS PER STOREY HEIGHT } \\
\hline \multicolumn{16}{|c|}{ ZONE-5 } \\
\hline \multicolumn{6}{|c|}{ SOIL-1 } & \multicolumn{5}{|c|}{ SOIL-2 } & \multicolumn{5}{|c|}{ SOIL-3 } \\
\hline \multicolumn{2}{|c|}{ B-S (W) } & \multicolumn{2}{|c|}{ B-S (1) } & \multicolumn{2}{|c|}{ B-S (2) } & \multirow{2}{*}{$\begin{array}{c}\text { B-S (W) } \\
\text { DRIFT }\end{array}$} & \multicolumn{2}{|c|}{ B-S (1) } & \multicolumn{2}{|c|}{ B-S (2) } & \multirow{2}{*}{$\begin{array}{c}\text { B-S (W) } \\
\text { DRIFT }\end{array}$} & \multicolumn{2}{|c|}{ B-S (1) } & \multicolumn{2}{|c|}{ B-S (2) } \\
\hline $\begin{array}{c}\text { STOREY } \\
\text { HT. }\end{array}$ & DRIFT & DRIFT & $\begin{array}{l}\text { (RC- } \\
\text { l) }\end{array}$ & DRIFT & $\begin{array}{l}\text { (RC- } \\
2)\end{array}$ & & DRIFT & $\begin{array}{l}\text { (RC- } \\
\text { l) }\end{array}$ & DRIFT & $\begin{array}{l}\text { (RC- } \\
2)\end{array}$ & & DRIFT & $\begin{array}{l}\text { (RC- } \\
\text { l) }\end{array}$ & DRIFT & $\begin{array}{c}\text { (RC- } \\
2)\end{array}$ \\
\hline 90 & 3.09 & 5.97 & -0.93 & 5.74 & -0.86 & 4.27 & 8.07 & -0.89 & 7.77 & -0.82 & 5.28 & 9.88 & -0.87 & 9.51 & -0.11 \\
\hline 87 & 4.37 & 5.95 & -0.36 & 5.72 & -0.31 & 5.94 & 8.06 & -0.36 & 7.76 & -0.31 & 7.29 & 9.88 & -0.36 & 9.51 & -0.05 \\
\hline 84 & 5.49 & 6.00 & -0.09 & 5.779 & -0.05 & 7.47 & 8.14 & -0.09 & 7.85 & -0.05 & 9.17 & 9.97 & -0.09 & 9.64 & -0.01 \\
\hline 81 & 6.57 & 6.07 & 0.08 & 5.872 & 0.11 & 8.93 & 8.24 & 0.08 & 7.99 & 0.11 & 10.96 & 10.11 & 0.08 & 9.81 & 0.03 \\
\hline 78 & 7.57 & 6.16 & 0.19 & 5.99 & 0.21 & 10.29 & 8.37 & 0.19 & 8.15 & 0.21 & 12.63 & 10.27 & 0.19 & 10.01 & 0.06 \\
\hline 75 & 8.50 & 6.27 & 0.26 & 6.118 & 0.28 & 11.55 & 8.51 & 0.26 & 8.32 & 0.28 & 14.17 & 10.44 & 0.26 & 10.21 & 0.09 \\
\hline 72 & 9.35 & 6.37 & 0.32 & 6.242 & 0.33 & 12.70 & 8.64 & 0.32 & 8.48 & 0.33 & 15.58 & 10.60 & 0.32 & 10.41 & 0.11 \\
\hline 69 & 10.12 & 6.46 & 0.36 & 6.358 & 0.37 & 13.74 & 8.77 & 0.36 & 8.63 & 0.37 & 16.86 & 10.75 & 0.36 & 10.59 & 0.14 \\
\hline 66 & 10.81 & 6.53 & 0.40 & 6.447 & 0.40 & 14.68 & 8.86 & 0.40 & 8.75 & 0.40 & 18.02 & 10.86 & 0.40 & 10.73 & 0.16 \\
\hline 63 & 11.43 & 6.53 & 0.43 & 6.429 & 0.44 & 15.49 & 8.86 & 0.43 & 8.72 & 0.44 & 18.98 & 10.86 & 0.43 & 10.70 & 0.18 \\
\hline 60 & 8.51 & 6.57 & 0.23 & 6.454 & 0.24 & 11.59 & 8.90 & 0.23 & 8.75 & 0.24 & 14.24 & 10.91 & 0.23 & 10.73 & 0.07 \\
\hline 57 & 8.82 & 6.57 & 0.25 & 6.453 & 0.27 & 11.99 & 8.90 & 0.26 & 8.74 & 0.27 & 14.71 & 10.90 & 0.26 & 10.72 & 0.08 \\
\hline 54 & 9.12 & 6.55 & 0.28 & 6.433 & 0.29 & 12.39 & 8.87 & 0.28 & 8.71 & 0.30 & 15.20 & 10.86 & 0.29 & 10.68 & 0.09 \\
\hline 51 & 9.38 & 6.51 & 0.31 & 6.384 & 0.32 & 12.74 & 8.80 & 0.31 & 8.64 & 0.32 & 15.64 & 10.78 & 0.31 & 10.59 & 0.10 \\
\hline 48 & 9.61 & 6.42 & 0.33 & 6.294 & 0.34 & 13.05 & 8.68 & 0.33 & 8.52 & 0.35 & 16.01 & 10.63 & 0.34 & 10.44 & 0.11 \\
\hline 45 & 9.80 & 6.29 & 0.36 & 6.152 & 0.37 & 13.30 & 8.50 & 0.36 & 8.32 & 0.37 & 16.32 & 10.41 & 0.36 & 10.19 & 0.11 \\
\hline 42 & 9.95 & 6.21 & 0.38 & 6.071 & 0.39 & 13.51 & 8.40 & 0.38 & 8.22 & 0.39 & 16.57 & 10.29 & 0.38 & 10.07 & 0.12 \\
\hline 39 & 10.06 & 6.01 & 0.40 & 5.871 & 0.42 & 13.66 & 8.14 & 0.40 & 7.96 & 0.42 & 16.75 & 9.98 & 0.40 & 9.76 & 0.12 \\
\hline 36 & 10.15 & 5.80 & 0.43 & 5.648 & 0.44 & 13.76 & 7.85 & 0.43 & 7.66 & 0.44 & 16.88 & 9.63 & 0.43 & 9.38 & 0.13 \\
\hline 33 & 10.18 & 5.54 & 0.46 & 5.379 & 0.47 & 13.81 & 7.50 & 0.46 & 7.29 & 0.47 & 16.93 & 9.19 & 0.46 & 8.93 & 0.13 \\
\hline 30 & 9.63 & 5.25 & 0.45 & 5.077 & 0.47 & 13.08 & 7.11 & 0.46 & 6.88 & 0.47 & 16.05 & 8.72 & 0.46 & 8.43 & 0.12 \\
\hline 27 & 9.62 & 4.97 & 0.48 & 4.754 & 0.51 & 13.06 & 6.72 & 0.49 & 6.44 & 0.51 & 16.03 & 8.23 & 0.49 & 7.89 & 0.13 \\
\hline 24 & 9.60 & 4.63 & 0.52 & 4.442 & 0.54 & 13.03 & 6.27 & 0.52 & 6.01 & 0.54 & 15.99 & 7.67 & 0.52 & 7.36 & 0.13 \\
\hline 21 & 9.55 & 4.24 & 0.56 & 4.065 & 0.57 & 12.96 & 5.74 & 0.56 & 5.50 & 0.58 & 15.90 & 7.03 & 0.56 & 6.74 & 0.14 \\
\hline 18 & 9.46 & 3.78 & 0.60 & 3.623 & 0.62 & 12.83 & 5.13 & 0.60 & 4.92 & 0.62 & 15.74 & 6.29 & 0.60 & 6.03 & 0.14 \\
\hline 15 & 9.29 & 3.27 & 0.65 & 3.14 & 0.66 & 12.60 & 4.44 & 0.65 & 4.27 & 0.66 & 15.45 & 5.45 & 0.65 & 5.24 & 0.14 \\
\hline 12 & 8.97 & 2.71 & 0.70 & 2.607 & 0.71 & 12.16 & 3.69 & 0.70 & 3.54 & 0.71 & 14.92 & 4.52 & 0.70 & 4.35 & 0.14 \\
\hline 9 & 8.31 & 2.09 & 0.75 & 2.008 & 0.76 & 11.26 & 2.84 & 0.75 & 2.73 & 0.76 & 13.80 & 3.48 & 0.75 & 3.35 & 0.13 \\
\hline 6 & 6.81 & 1.39 & 0.80 & 1.334 & 0.80 & 9.22 & 1.89 & 0.80 & 1.82 & 0.80 & 11.29 & 2.32 & 0.79 & 2.23 & 0.11 \\
\hline 3 & 3.52 & 0.58 & 0.84 & 0.543 & 0.85 & 4.63 & 0.70 & 0.85 & 0.68 & 0.85 & 5.59 & 0.87 & 0.84 & 0.85 & 0.06 \\
\hline
\end{tabular}
in $[\mathrm{B}-\mathrm{S}(\mathrm{W})]$ 


\section{STOREY HEIGHT V/S DRIFT REDUCTION FACTOR FOR ZONE-5} IN DIFFERENT SOIL CONDITIONS

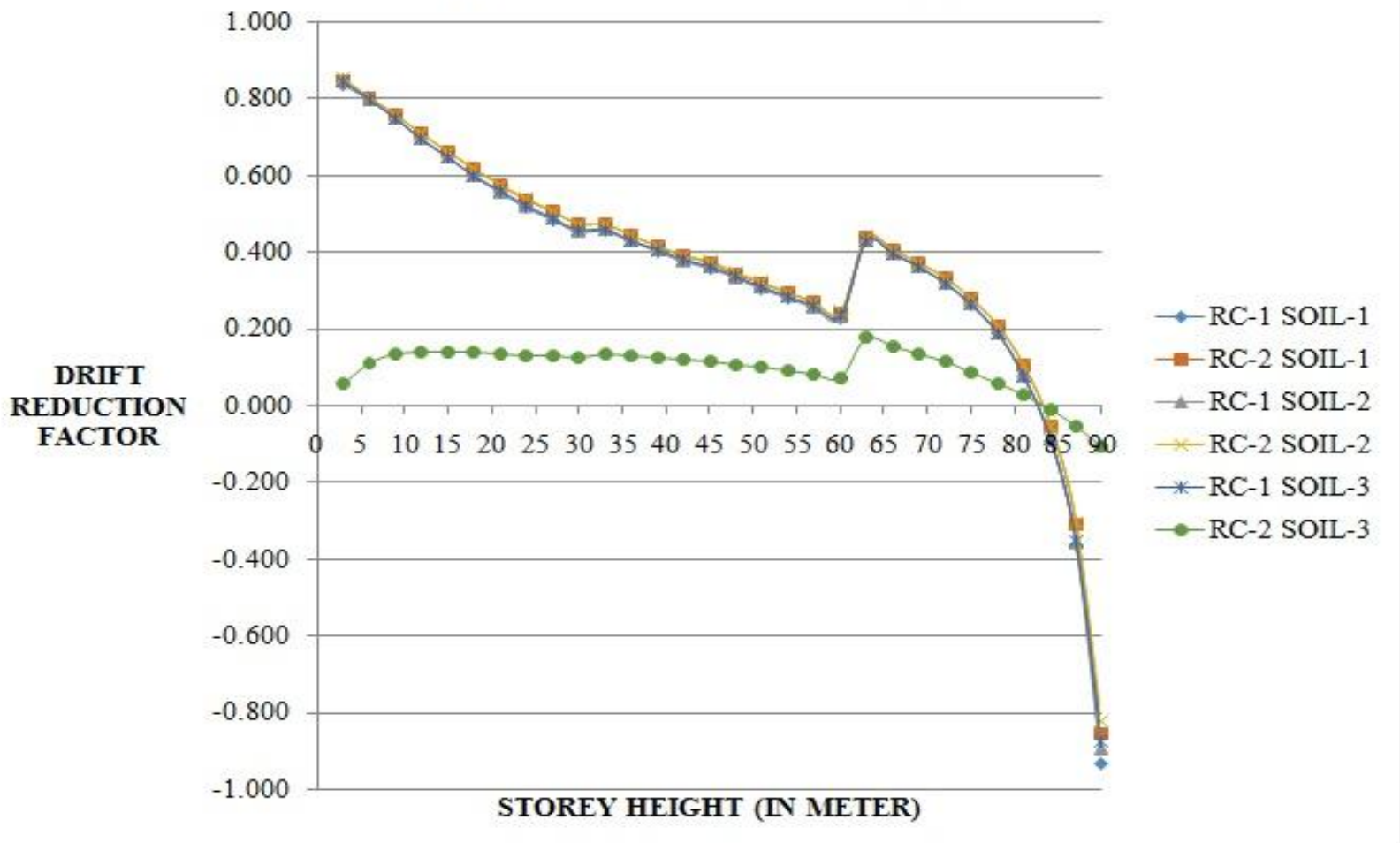

Fig. 5 Graph in Between Storey Height V/S Drift Reduction Factor for Zone-5 in Different Soil Conditions

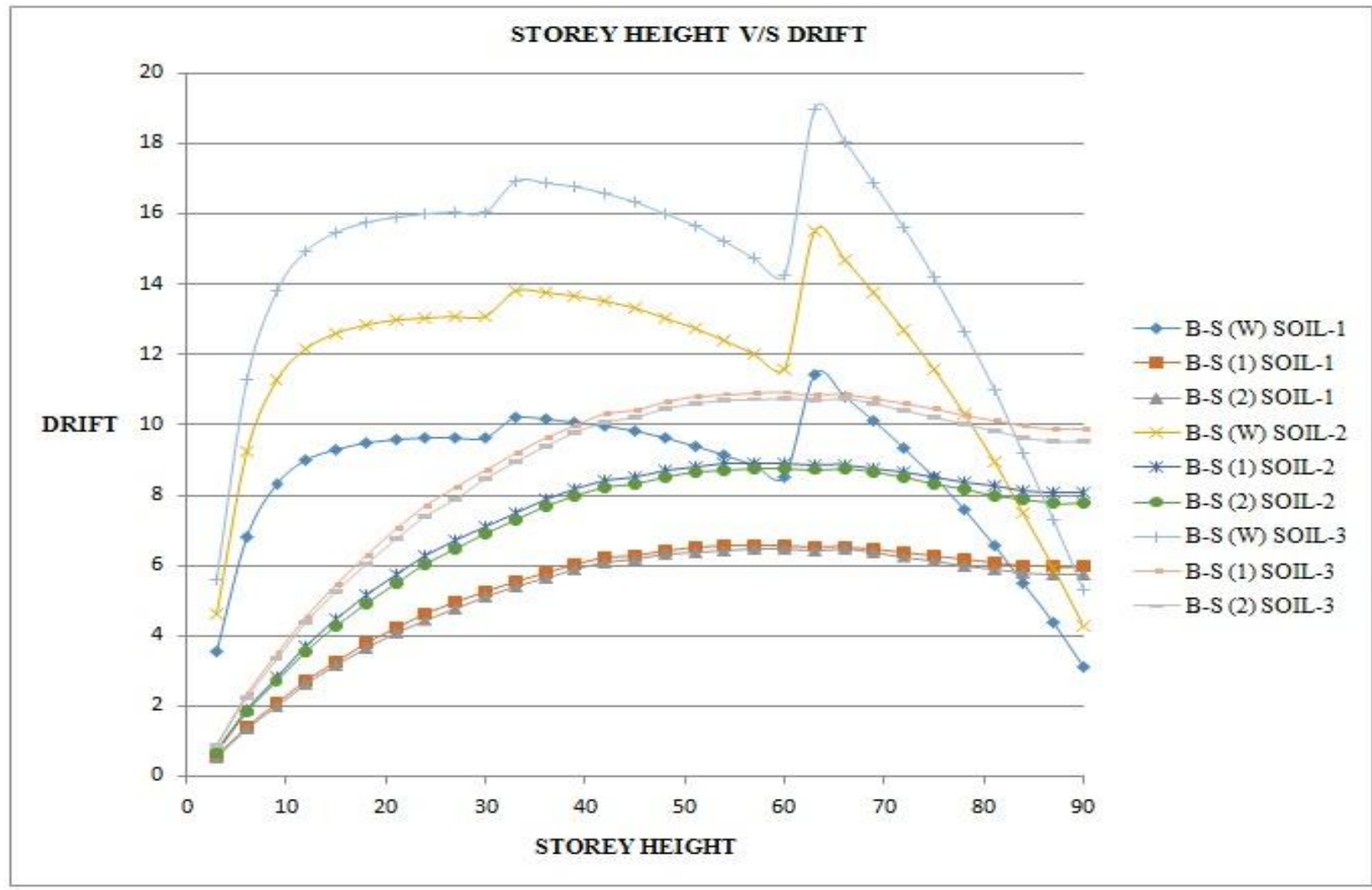

Fig. 6 Graph in Between Storey Height V/S Drift 


\section{CONCLUSION-}

a) In building having no shear wall drift increases in initial 4 or 5 stories there after it remain constant about $2 / 3$ of total height and then it decreases. A kink is observed where column sections are changed.

b) Irrespective of type of provision of shear wall. In case of $90 \mathrm{~m}$ height building drift increases gradually up to $1 / 2$ of total height and there after it is almost constant in all the cases. In all the cases it is well within permissible limit.

c) In case where full shear wall and Stepped shear wall show proper drift reduction factor upto $3 / 4$ of total height.

d) Gradual reduction in thickness of shear wall has better drift control.

e) For soil condition hard and medium the drift reduction factor decrease drastically in above storey due to which shear wall acts negatively in drift control as compare to frame structure.

f) For soil condition soft stepped shear wall show proper drift control.

g) Gradual reduction shear wall maybe saved in investment without impairing structural strength.

h) For Different cases of $90 \mathrm{~m}$ heighted building for different condition of soil in which the permissible drift exceed for soft soil condition especially where column section and Shear wall section are changes up kink sudden change observed.

\section{REFERENCES}

[1] Venkatesh M. B., R. D. Deshpande, Analysis of R.C. building frame with raft foundation considering soil structure interaction, International Research Journal of Engineering and Technology, Vol. 4, No. 5, 2017,752-760.

[2] Aparna Obulasetti, Mr. V Srinivsa Rao, Mr. K. Sundara Kumar, Seismic analysis of RC framed office building considering soil structure interaction, International Journal For Technological Research In Engineering Vol. 4, No. 4, 2016,624-628.

[3] Maikesh Chouhan, Ravi Kumar Makode, Dynamic Analysis of Multi-Storeyed Frame-Shear Wall Building Considering SSI, International Journal of Engineering Research and Application,Vol. 6,No. 8, 2016, 31-35.

[4] Anuradha Dr. H.M.Somasekharaiah,, Soil Structure Interaction Effect on the Dynamic Behavior of Irregular R.C. Frame with Isolated Footings, International Journal for Scientific Research \& Development, Vol. 3, No. 4, 2015, 2019-2024.
[5] Anila Anna Samson, Preetha Prabhakaran, Dr. Girija K ,Performance of shear wall building during Seismic Excitations, International Journal of Civil engineering and Technology, Vol. 5, No. 12, 2014,7383.

[6] D. K. Jain and M. S. Hora, Interaction analysis of space frame-shear wall-Soil System to Investigate foundation forces under Seismic loading, ARPN Journal of Engineering and Applied Sciences, VOL. 9, NO. 8,2014,1267-1281.

[7] Shehata e. Abdel raheem, Mohamed m. ahmed and Tarek m.a. alazrak, SoilStructure Interaction effects on seismic response of multi-story buildings on raft foundation, Journal of Engineering Sciences, Assiut University, Faculty of Engineering, Vol. 42 No. 4, 2014, 905930.

[8] Er. Puneet Sharma, Er. Ankit, Er. Ismit Pal Singh, Soil Structure Interaction Effect on an Asymmetrical R.C. Building with Shear Walls, IOSR Journal of Mechanical and Civil Engineering, Vol. 11, No. 3, 2014, 45-56.

[9] H.K Chinmayi, B.R Jayalekshmi, Soilstructure interaction analysis of RC frame shear wall buildings over raft foundations under seismic loading,,International Journal of Scientific \& Engineering Research,Vol. 4,No. 5,2013.99-102.

[10] Ravikanth Chittiprolu, Ramancharla Pradeep Kumar, Significance of Shear Wall in High-rise Irregular Buildings, International Journal of Education and Applied Research (IJEAR) Vol. 4, No. 2, 2014, 35-37.

[11] R. M. Jenifer Priyanka, N. Anand, Dr. S. Justin, Studies on Soil Structure Interaction of Multi Storeyed Buildings with Rigid and Flexible Foundation, International Journal of Emerging Technology and Advanced Engineering, Vol. 2, No. 12, 2012, 111-118.

[12] IS 1893 (Part 1)-2002: Indian Standard Criteria for Earthquake Resistant Design of Structures, Part 1-General Provisions and Buildings (Fifth Revision), Bureau of Indian Standards, New Delhi.

[13] IS: 456.2000. Indian standard "plain and reinforced concrete" -code of practice, Bureau of Indian standards, New Delhi. 